\title{
Analysis of electricity loss calculation methods in distribution networks
}

\author{
Abat Muratov $^{1}$, Zlixa Saparniyazova ${ }^{1}$, I I Bakhadirov ${ }^{2}$, Alibiy Bijanov ${ }^{1}$ \\ ${ }^{1}$ Karakalpak State University \\ ${ }^{2}$ Tashkent State Technical University
}

\begin{abstract}
The article provides an analysis of methods for calculating electricity losses. The conditions for the application of methods for calculating electricity losses are determined, and structural separated losses in electrical networks are shown. A modern classification of losses is presented, and methods for calculating technological losses of electricity are considered.
\end{abstract}

Key words: time of maximum losses, rms current.

\section{Introduction}

Organizational and economic delimitation of the processes of generation, transmission, sales, dispatching, repair and other types of activities has led to the emergence of new economic entities, in the regulation of which, an important role is played by the mechanisms of market relations. In this regard, special attention is paid to monitoring and optimal management of the processes of production, transmission, distribution and consumption of $\mathrm{EE}$, which in this case is a commercial product.

One of the significant indicators affecting the economic efficiency of the functioning of the power system as a whole, and in particular of grid companies, is the value of electricity losses (EE). Accurate and reliable determination of this integral indicator of the operating mode is the basis for solving the problems of analyzing EE losses, developing organizational and technical measures for effective management, determining the standard value of EE losses, and setting EE tariffs [1-10].

\section{Main part}

Depending on the time of performing calculations of electricity losses, there are three types of calculations, each of which pursues its own goals (Fig. 1).

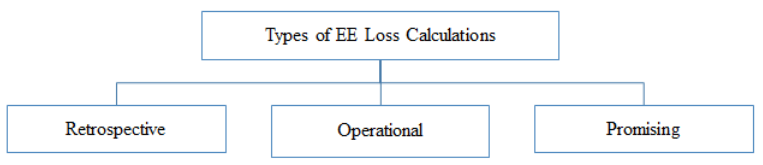

Fig. 1. Types of calculations of EE losses

Retrospective calculations (for the past time intervals) determine the electricity losses over the past time intervals and are used to:

-determination of the structure of electricity losses, -estimates of commercial losses,

-identification of groups of network elements with increased losses,

-drawing up balances of electricity in general, its structural divisions and substations,

-determination of technical and economic indicators of the power system.

Operational calculations (for current time intervals) determine losses for current time intervals and are used to:

-control over the current values of electricity losses,

-operative adjustment of the current mode in order to minimize energy losses,

-forming a retrospective database to determine the structure of electricity losses by groups of elements of the electrical network.

Prospective calculations (estimation of expected losses in the future) determine the expected losses of electricity for the next and subsequent years and serve to:

-determination of the expected losses of electricity for the next years;

-estimation of the expected effectiveness of the planned measures to reduce losses;

-comparison of options for the reconstruction of electrical networks.

The classification of methods for calculating load losses of electricity is as follows (Fig. 2):

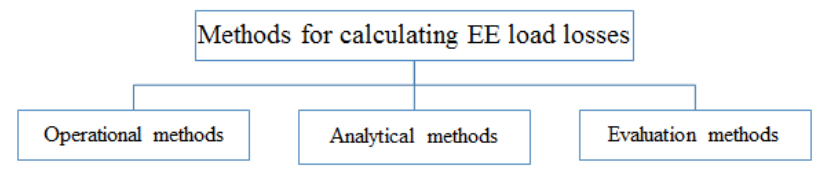

Fig. 2. Calculation of EE load losses

Operational methods of calculation involve obtaining the necessary information and performing calculations of the mode and load losses of electricity at the "rate of the process".

Analytical methods are based on the calculation of power 
and electricity losses in a limited number of modes and the use of the characteristics of the load curves (calculation of the mode during the maximum period, based on average indicators, etc.) [11-17].

Estimation methods are based on the use of probabilistic characteristics and generalized information.

The following deterministic methods can be used to calculate the load losses of electricity for the billing period, depending on the amount of available information about the circuits and loads of networks: typical days; medium loads; the number of hours of the greatest power losses; rms current.

Of these methods, the most accurate is the method of calculating the energy losses in the network for a characteristic day and is equivalent to the number of days of their duration. According to this method, a characteristic day is outlined within the calculation period. For each of the selected days, load graphs are compiled, which are presented in the form of stepped lines, and at each stage of the graph, the load remains unchanged. The formula for calculating losses using this method is as follows:

$$
\Delta W_{l}=\sum_{i=1}^{m} \Delta W_{l i} D_{e k i}
$$

Where $\mathrm{m}$ - the number of characteristic days, the loss of electricity for each of which, calculated according to the known load curves at the network nodes, is $\Delta W_{\mu i}$; $D_{e k i}$ - the equivalent number of days in the $i$-th calculation interval.

For approximate calculations, they are guided only by typical days: two operating days a year (reference day) - days of maximum and minimum load (winter and summer) of the network. Then the energy loss [18-24]:

$$
\Delta W_{l}=\Delta W_{l}^{3} D_{e k}^{3}+\Delta W_{l}^{l} D_{e k}^{l}
$$

Under operating conditions, load curves are formed on the basis of special measurements on a typical day of the year. The disadvantages of the method include the fact that it involves the use of graphs of total rather than active power, which are less accurate. In addition, the calculation results reflect the change in the network scheme during the year, the dynamics of the loads, the change in the loads of power plants, etc.

Therefore, the energy losses calculated for a typical day do not remain unchanged during the entire period characteristic of this day.

The error of this method is completely determined by the off-season inhomogeneity of the graphs. In networks with a small number of generating nodes, it does not exceed 3-5\%.

This method can also be used for calculating variable losses of energy efficiency of main networks in the case when there are no initial data using the method of operational calculations, as well as for lower voltage networks if there is appropriate initial information [25-29].

Of interest is the method for calculating energy losses using a probabilistic characteristic - the average load in its numerical discrete form [6]. The calculation of variable EE losses in the elements of the electrical network is carried out on the basis of certain power losses obtained from the results of calculating the operating parameters of the network.

According to this technique, when calculating energy losses, a formula is used that has the following form:

$$
\Delta W_{l}=\Delta P_{a l} K_{f}^{2} T
$$

where $\Delta P_{a l^{-}}$power losses in the network at average loads of nodes (or the network as a whole) for the calculated period $\mathrm{T} ; \mathrm{K}_{\mathrm{f}}$ is the shape factor of the load graph.

In practical calculations, $\mathrm{P}_{\mathrm{al}}$ can be determined from meter readings or from known load change limits.

It should be noted that with a small information error for circuits with a configuration unchanged during a period and little changing loads, this method can give an accuracy acceptable for practical purposes. The expected accuracy of the method is within $10-11 \%$. Average load methods are applicable with relatively uniform node load curves. They are recommended as preferable for open networks in the presence of data on the electricity passed through the head section of the network during the period under consideration. Lack of data suggests homogeneity.

Calculation of losses using simplified models is widely used in calculation practice. This approach, based on fixing the time of maximum losses, does not impose strict requirements on the accuracy of calculations. The algorithm for calculating energy efficiency losses by the time of maximum losses $\tau$, which is strictly justified for one section of the network with a typical load graph, has the following form:

$$
\Delta W_{l}=\Delta P_{\max } \tau
$$

The maximum losses $\Delta P_{\max }$ are determined from the maximum load, which in turn is determined from the expected energy flow and the duration of the maximum load use.

The time of greatest losses $t$ is the time during which, when transmitting the greatest load in the network, the same electricity losses will occur as when the network operates according to the actual load schedule. The following dependencies are used to determine $\mathrm{t}$ :

$$
\tau=\frac{\Sigma S_{j}^{2} \Delta t_{j}}{S_{\max }^{2}} \quad \tau=\left(0.124+T_{\max } \cdot 10^{-4}\right)^{2} \cdot 8760
$$

In computational practice, to determine the time of greatest losses, the dependences of A.A. Glazunov, A.Ya. Ryabkov, V.V. Kezevich, V.V. Ershevich are also used. and others. Each of these dependencies is obtained for specific conditions and therefore has its own outlined area of application.

The fundamental point of this method is the assumption that the maximum energy losses in the calculated network element are observed at the maximum system load, and the configurations of the active and reactive power graphs are homogeneous $(\cos \varphi=$ const $)$.

Due to the fact that the last condition is met extremely rarely even in distribution networks, recommendations have appeared on the separate determination of losses for active and reactive loads. In this case, the calculation of losses is carried out according to:

$$
\Delta W_{H}=\Delta P_{\max , a} \tau_{a}+\Delta P_{\max , p} \tau_{p}
$$

Where $\tau_{a}$ and $\tau_{p}$ determined by the analysis of real flow graphs.

The assumptions made in this method about the load model of the element (constant maximum load during the period $\mathrm{T}_{\max }$ ) and about the network model (the network has 
constant parameters throughout the analysis period) limit the scope of its application to distribution networks with a small number of participants or estimated design calculations of energy losses in separate lines without taking into account the influence of the mode of this transmission line on the closed network mode as a whole. The error of the method is estimated at $\pm 10-25 \%$ for open distribution networks.

In the presence of the necessary initial data, the methods of average loads and the number of hours of greatest losses are allowed to perform calculations of electricity losses in electrical networks of $0.4 \mathrm{kV}$ [30-34].

One of the first methods in terms of time of creation is the method of rms current. The method directly follows from the physical nature of the power losses, which in the network element are proportional to the square of the total load.

The rms current $I_{\text {rms }}$ is such a conventional constant in magnitude current, when it flows through the network during the calculated period, the same energy losses are released as when the actual current flows, changing according to the load curve.

Passing to the EE losses, for the time T we get:

$$
\Delta W_{l}=3 R \int_{0}^{T} I^{2}(t) d t=3 I_{r m s}^{2} R T
$$

Initially, a full equivalent circuit was used as a model of the electrical network for which the energy loss was calculated. But with the development of networks and the difficulties that arose in obtaining information about the mode of all elements of the network, the equivalent circuit of the network began to be reduced to one element with the load of the head section and the equivalent resistance Req. At the same time, the values of $\mathrm{I}_{\mathrm{rms}}$ for the billing period began to be taken equal to the value calculated according to the daily load schedule. Calculation of $\mathrm{I}_{\mathrm{rms}}$ according to the daily schedule is a rough simulation of the network. Errors in this case can reach up to $30 \%$. This prompted the development of this method. One of the ways of which is to determine the rms current from the value of the average current [35-40]:

$$
I_{r m s}=K_{f} I_{a}
$$
$\mathrm{I}_{\mathrm{rms}}$.

There are also known other dependencies for calculating

\section{Colculation}

1. This method is classified as an approximate one, and it is used to calculate the load losses of the EE of $6-10 \mathrm{kV}$ distribution networks. It can also be recommended for lower voltage networks. The main advantage of this method is that the RMS current is calculated only once for a series of calculations.

2. In the practice of calculating EE losses in distribution networks, especially in 10-6 kV RS, methods using generalized factors of circuits and modes in the form of regression equations have found wide application. At the same time, it is very important that the most significant and independent factors enter the equation. The input of active energy $\mathrm{W}$, the total length of the line L, the number of sections of the line $\mathrm{m}$, the total number of transformers $\mathrm{N}_{\mathrm{tr}}$ and their total installed power $S_{\text {tr }}$, etc. are considered as factors.

\section{Reference}

1. TAN Mu-zi, LI Xiao-song, Calculation of Theoretical Line Loss for Rural Low-Voltage Distribution Networks under Unbalanced Three-Phase Loads based on Time Segment, Journal of Hunan Institute of Science and Technology (Natural Sciences), 2015, (1).

2. Houdek V., Sojka J., Rusek S., Gono R.: Backup alternatives for $110 \mathrm{kV}$ lines. International Scientific Conference Electric Power Engineering 2012. May 2021, Brno Czech Republic ISBN 978-80-214-4514-7 (str. 929934).

3. Carpaneto, E.; Chicco, G.; Sumaili Akilimali, J. Loss partitioning and loss allocation in three-phase radial distribution systems with distributed generation. IEEE Trans. Power Syst. 2008, 23, 1039-1049.

4. Atanasovski, M.; Taleski, R. Energy summation method for loss allocation in radial distribution networks with DG. IEEE Trans. Power Syst. 2012, 27, 1433-1440.

5. I.Rakhmonov, A.Berdishev, N.Niyozov, A.Muratov and U.Khaliknazarov. Development of a scheme for generating the predicted value of specific electricity consumption // CONMECHYDRO - 2020. IOP Conf. Series: Materials Science and Engineering. $883 \quad$ (2020) 012103. doi:10.1088/1757-899X/883/1/012103

6. F.A.Hoshimov, I.I.Bakhadirov, M.S.Kurbanbayeva, N.A.Aytbayev. Development of specific standards of energy consumption by types of produced products of the spinning product // RSES 2020. E3S Web of Conferences. 216 (2020) 01169. https://doi.org/10.1051/e3sconf/202021601169
7. F.A.Hoshimov,
I.I.Bakhadirov,
A.A.Alimov,

M.T.Erejepov. Forecasting the electric consumption of objects using artificial neural networks // E3S Web of $\begin{array}{llll}\text { Conferences. } & 216 & \text { (2020) } & 01170 .\end{array}$ https://doi.org/10.1051/e3sconf/202021601170

8. I.Rakhmonov, A.Berdishev, B.Khusanov, U.Khaliknazarov, U.Utegenov. General characteristics of networks and features of electricity consumers in rural areas // CONMECHYDRO - 2020. IOP Conf. Series: Materials Science and Engineering. $883 \quad$ (2020) 012104. doi:10.1088/1757-899X/883/1/012104

9. R.Karimov, M.Bobojanov. Analysis of voltage stabilizers and non-contact relays in power supply systems // RSES 2020. E3S Web of Conferences. 216 (2020) 01162. https://doi.org/10.1051/e3sconf/202021601162

10. R.Karimov. Study of the state of the issue of increasing the quality of electric energy in the power supply systems // RSES 2020. E3S Web of Conferences. 216 (2020) 01163. https://doi.org/10.1051/e3sconf/202021601163

11. I.U.Rakhmonov, A.N.Tovbaev, L.A.Nematov and T.Sh.Alibekova. Development of forecasted values of specific norms for the issues of produced products in industrial enterprises // ICMSIT-2020. Journal of Physics: Conference Series. 1515 (2020) 022050. doi:10.1088/17426596/1515/2/022050

12. I.U.Rakhmonov, L.Nematov, N.N.Niyozov, K.M.Reymov, T.Yuldoshev. Power consumption management from the positions of the general system theory 
// ICMSIT-2020. Journal of Physics: Conference Series. 1515 (2020) 022054. doi:10.1088/1742-6596/1515/2/022054

13. I.U.Rakhmonov, F.A.Hoshimov. Development of an algorithm for evaluating the dominant factors that have the greatest impact on the energy intensity of products // ENERGY-21. E3S Web of Conferences. 209 (2020) 07018. https://doi.org/10.1051/e3sconf/202020907018

14. Usmanov E.G. Stability in a parallel resonant circuit with active load // RSES 2020. E3S Web of Conferences. 216 (2020) 01160. https://doi.org/10.1051/e3sconf/202021601160 15. Usmanov E.G., Khusanov B.M. Phase relations in resonant circuits with a wide falling section on the amplitude characteristic // RSES 2020. E3S Web of Conferences. 216 (2020) 01161. https://doi.org/10.1051/e3sconf/202021601161 16. I.U.Rakhmonov, K.M.Reymov and S.H.Dustova. Improvements in industrial energy rationing methods // MIP: Engineering-2020. E3S Web of Conferences. 862 (2020) 062070. doi:10.1088/1757-899X/862/6/062070

17. I.U.Rakhmonov, K.M.Reymov. Statistical models of renewable energy intermittency // RSES 2020. E3S Web of $\begin{array}{llll}\text { Conferences. } & 216 & \text { (2020) } & 01167 .\end{array}$ https://doi.org/10.1051/e3sconf/202021601167

18. I.U.Rakhmonov, N.N.Kurbonov. Analysis of automated software for monitoring energy consumption and efficiency of industrial enterprises // E3S Web of Conferences. 216 (2020) 01178. https://doi.org/10.1051/e3sconf/202021601178 19. F.A.Hoshimov, I.U.Rakhmonov, N.N.Niyozov. Technology to reduce energy costs in the electric steel melting shop // ENERGY-21. E3S Web of Conferences. 209 (2020) 07017. https://doi.org/10.1051/e3sconf/202020907017 20. A.Taslimov, F.Rakhimov, L.Nematov, N.Markaev, A.Bijanov, R.Yunusov. Economic load intervals for selecting $10 \mathrm{kV}$ cable cross-sections for agricultural consumers // CONMECHYDRO - 2020. IOP Conf. Series: Materials Science and Engineering. $883 \quad$ (2020) 012102. doi:10.1088/1757-899X/883/1/012102

21. A.Taslimov, M.Melikuziev, O.Matchonov, M.Ruzinazarov and M.Nasirov. Development of standard cable cross-sections of rural electrical networks // CONMECHYDRO - 2020. IOP Conf. Series: Materials Science and Engineering. $883 \quad$ (2020) 012105. doi:10.1088/1757-899X/883/1/012105

22. A.D.Taslimov, F.M.Rakhimov,

A.O.Norkulov, A.A.Yuldashev. Research of the optimum scale of standard sections of agricultural purpose lines // E3S Web of Conferences. $216 \quad$ (2020) https://doi.org/10.1051/e3sconf/202021601158

23. A.D.Taslimov., M.V.Melikuziev, A.M.Najimova, A.A.Alimov. Economic load intervals for selection of cable sections for agricultural purpose // E3S Web of Conferences. 216 (2020)

01159.

https://doi.org/10.1051/e3sconf/202021601159

24. Hadha Afrisal, Budi Setiyono, Muhammad Fahmi Yusuf, Rose Mutiara Suin, Olimjon Toirov 2020 7th International Conference on Information Technology, Computer, and Electrical Engineering (ICITACEE), pp. 4146

(2020),

https://doi.org/10.1109/ICITACEE50144.2020.9239228

25. Kamoliddin Alimkhodjaev, Olimjon Toirov, Mirzohid Taniev, Sharofiddin Alimkhodjaev Addressing Issues and Possibility of Introducing Renewable Energy Sources in the
Conditions of Uzbekistan. JCR. 7(15), 1721-1728 (2020), doi:10.31838/jcr.07.15.231

26. Olimjon Toirov, Kamoliddin Alimkhodjaev, Akhror Pardaboev Analysis and ways of reducing electricity losses in the electric power systems of industrial enterprises, E3S Web of Conferences, SUSE-2021 (2021)

27. Abduazizov N.A., Muzaffarov A., Toshow J.B., Juraev R.U., Zhuraev A.Sh. A complex of methods for analyzing the working fluid of a hydrostatic power plant for hydraulic mining machines // International Journal of Advanced Science and Technology. Vol. 29, No. 5s, (2020), pp. 852855

28. Baratov B., Toshov J., Baynazov U. Method of calculating the gear ratios of the cones of tricone drill bits // E3S Web Conf., Volume 201, 01012, 2020, Ukrainian School of Mining $\quad$ Engineering - 2020. https://doi.org/10.1051/e3sconf/202020101012

29. Haqberdiev A., Toshov J. Analysis of the control system of electric motors of the running gear of self-propelled mine cars used in complex mining and technological conditions // E3S Web of Conferences 216, 01135 (2020), Rudenko International Conference "Methodological problems in reliability study of large energy systems" (RSES 2020), https://doi.org/10.1051/e3sconf/202021601135

30. K.M.Reymov, G.Turmanova, S.Makhmuthonov, B.Uzakov. Mathematical models and algorithms of optimal load management of electrical consumers // E3S Web of Conf. $216 \quad 01166$. https://doi.org/10.1051/e3sconf/202021601166

31. Yu.M.Bobozhonov, K.M.Reymov, B.T.Seytmuratov, T.Kh.Khakimov. Research of the dependence of the resistance of asynchronous generators with massive rotors on their design // RSES 2020. E3S Web of Conferences. 216 (2020) 01168. https://doi.org/10.1051/e3sconf/202021601168 32. Rakhmonov I U, Reymov K M, Najimova A M, Uzakov B T and Seytmuratov BT 2019 Analysis and calculation of optimum parameters of electric arc furnace Journal of Physics: Conference Series 1399 doi:10.1088/17426596/1399/5/055048

33. Toshniyozov L.G., Toshov J.B. Theoretical and experimental research into process of packing in drilling. MIAB. Mining Inf. Anal. Bull. 2019;(11):139-151. [In Russ]. DOI: $10.25018 / 0236-1493-2019-11-0-139-151$.

34. Toshov J.B. The questions of the dynamics of drilling bit on the surface of well bottom// Arch. Min. Sci. - Poland. Vol. 61 (2016), № 2, P. 279-287. DOI 10.1515/amsc-20160020

35. Toshov Zh.B. Ways towards optimization of washout components of rock cutting tools // «GORNYI ZHURNAL»/«MINING JOURNAL», Moscow, 2016, № 2, pp. 21-24. DOI: http://dx.doi.org/10.17580/gzh.

36. A.N.Rasulov, M.R.Ruzinazarov, N.Toirova, T.Sh.Alibekova. Graphical-analytical method for constructing load characteristics // RSES 2020. E3S Web of Conferences. $\quad 216 \quad 01171$. https://doi.org/10.1051/e3sconf/202021601171

37. Yu.Bobozhonov, B.Seytmuratov, B.Fayzullaev, A.Sultonov. Study of the influence of different designs of massive rotor of asynchronous generator on their maximum power // RSES 2020. E3S Web of Conferences. 216 (2020) 01177. https://doi.org/10.1051/e3sconf/202021601177 
38. Taslimov A D, Rakhmonov I U 2019 Optimization of complex parameters of urban distribution electric networks Journal of Physics: Conference Series 1399 doi:10.1088/1742-6596/1399/5/055046

39. Rakhmonov I U, Niyozov N N 2019 Optimization setting of steel-smelting industry in the issue of alloy steels E3S Web Conf 139 doi:10.1051/e3sconf/201913901077

40. Rakhmonov I U, Reymov K M and Shayumova Z M 2019 The role information in power management tasks. E3S Web Conf 139 doi:10.1051/e3sconf/201913901080 